Fanum

Sociológico

\section{Forum Sociológico}

Série II

$25 \mid 2014$

Número 25

\title{
O fenómeno da peopolização elevado ao último grau de iniquidade: $O$ casting couch na variante homicida
}

José Augusto dos Santos Alves

\section{(2) OpenEdition \\ Journals}

Edição electrónica

URL: https://journals.openedition.org/sociologico/917

DOI: 10.4000/sociologico.917

ISSN: 2182-7427

Editora

CICS.NOVA - Centro Interdisciplinar de Ciências Sociais da Universidade Nova de Lisboa

Edição impressa

Paginação: 73-80

ISSN: 0872-8380

Refêrencia eletrónica

José Augusto dos Santos Alves, «O fenómeno da peopolização elevado ao último grau de iniquidade: O casting couch na variante homicida», Forum Sociológico [Online], 25 | 2014, posto online no dia 10 novembro 2014, consultado o 30 março 2022. URL: http://journals.openedition.org/sociologico/917 ; DOI: https://doi.org/10.4000/sociologico.917

Este documento foi criado de forma automática no dia 30 março 2022

(C) CICS.NOVA 


\title{
O fenómeno da peopolização elevado ao último grau de iniquidade: $O$ casting couch na variante homicida
}

\author{
José Augusto dos Santos Alves
}

\section{Introdução}

1 Este texto tem vários e diversificados ingredientes, uma panorâmica contributiva para a tentativa de compreensão de um horizonte de chegada: o homicídio, fenómeno radical do casting couch, no quadro da cultura da peopolização $0^{1}$, da hipervisibilidade, um processo que se inicia no incontrolável desejo de ser people.

2 A inclinação para a rivalidade é inerente à natureza humana. Cada um, entre nós, tem uma propensão a comparar-se aos outros e procurar, por tal ou tal traço exterior, uma pequena superioridade, uma diferença simbólica em relação às pessoas com as quais convive. A natureza humana não se reduz a este traço, não se trata de julgá-la de um ponto de vista moral, apenas se constata. Esta forma de rivalidade simbólica observa-se em todas as sociedades. Além disso, grande número de sociedades produzem com maior ou menor facilidade a riqueza necessária para satisfazer as necessidades alimentares, alojamento, educação dos filhos, convivialidade, etc. Portanto, apesar das crises cíclicas, as sociedades produzem, geralmente, uma quantidade de riquezas bem superior à satisfação das suas necessidades. Porquê?, pode perguntar-se. Porque, para além das necessidades básicas e sobrevivência, longe dos limites da pobreza, trata-se de permitir aos seus membros que se diferenciem uns dos outros. Como é sabido, existem várias classes no seio da sociedade. Cada uma, entre elas, é regida pelo princípio da rivalidade ostentatória. E, em cada classe, os indivíduos tomam como modelo o comportamento em vigor na classe social superior, que mostra o padrão do que é bem, o que é distinto fazer. A classe social imitada toma, ela própria, o exemplo da classe social que lhe está 
acima na escala da fortuna. Este fenómeno mimético reproduz-se de baixo para cima, do mesmo modo que a classe situada no cume da escala define o modelo cultural geral do que é prestigioso, do que se impõe aos outros. Que se passa numa sociedade muito inigualitária, como é o caso das sociedades atuais? Gera-se um gasto enorme, porque o esbanjamento material da oligarquia - ela própria exposta à emulação ostentatória serve de exemplo a toda a sociedade. Cada um, ao seu nível, no limite dos seus rendimentos, e para além deles, procura adquirir bens e os signos mais valorizados. Media, publicidade, filmes, folhetins, revistas people, a peopolização, são os utensílios de difusão do modelo cultural dominante, pressionados por alavancas poderosas políticas, económicas e mediáticas - de que a oligarquia dispõe e usa a fim de manter os seus privilégios. Na verdade, o modelo cultural do consumo, que impregna toda a sociedade, define-lhe a normalidade (Veblen, 1970).

Articulada e concomitante com esta necessidade de celebrização, a tese do hiperconsumismo, e da sua imbricação com o conceito de peopolização, não pode ser aqui ignorada.

4 Os princípios e valores perderam-se, ou pelos menos reificaram-se, nesta lógica de um deus, objeto de valor de uso ou de troca, na lógica do consumo, sobretudo se pensarmos que cidadania, solidariedade, ética, ecologia são valores consumíveis, e até descartáveis, quando inapropriados ao efémero ou à conjuntura. $O$ indivíduo hiperconsumista é bem o produto da dissolução do espaço público democrático. O homo consumericus (consumere, ergo sum) determina uma nova identidade que penetra o novo espaço público reificado, numa era em que os costumes, a fé e a política concorrem cada vez menos para a constituição da identidade, e em que o consumo assume um papel de substituto. Existe uma dimensão hedonista do consumo que não é compensada ao nível dos valores e dos princípios, que ajudaram o homem a ser cidadão. Um hedonismo que não tem contrapartida ao nível do debate cidadão, do aprofundamento da cidadania, bem pelo contrário, dilui essa mesma cidadania numa época em que o megaconsumismo busca sempre novas experiências e novas sensações (veja-se o ritmo de apresentação de novidades no quadro da cultura das aparências - os fashionables, os automóveis, os telemóveis, etc.). Na impossibilidade de aí aceder, vive-se a ilusão, que consumimos na televisão ou nos media, do espetáculo e da evasão. Vivemos numa sociedade da deceção, como lhe chamou Gilles Lipovetsky (Lipovetsky, 2006), pelo que carrega de paradoxal (a possibilidade de ser e a impotência do não vir a ser), em que as expectativas não se realizam, ou são mesmo irrealizáveis, fragilizada a individuação que torna o cidadão dependente do consumo e da possibilidade de consumir objetos de valor de uso ou de valor de troca. Demonizar o consumo pode não ser a via mais adequada para a solução deste estado cadaveroso, contudo, o mesmo não pode dizer-se da sua função terapêutica, como forma de lixiviar as megalomanias da individuação, a metástase do ego, como o alcoólatra ou o heroinómano. Com efeito, se a dinâmica do megaconsumismo traduz exigências hedonísticas, ela revela também os males de ausência de outras vivências no seio do espaço público democrático dissolvido. Deus morreu (o Jesus Cristo, "guerrilheiro", já não responde aos apelos, já não é saída para os males da individuação), resta o consumo. A velha Igreja, assente na transcendência vertical, esgotou-se, a vindoura, assente no uso público da razão, na transcendência horizontal, na alteridade, diluiu-se. Só resta o consumo, esperando o recentrar e o revisitar dos valores que se perpetuaram em nome da dignidade e dos laços sociais que uniam o homem. 
5 Assim sendo, como definir peopolização? Peopolização é o nome dado às práticas dos meios de comunicação que fortalecem a chamada sociedade do espetáculo, como o reality show, com o culto das celebridades, mesmo que sejam celebridades produzidas, instantâneas e efémeras (Wolton, 2006: 66; 2007).

6 A peopolização designa especificamente um indivíduo ou categoria de indivíduos conhecidos pela sua mediatização ou, se quisermos, de maneira metonímica, os media orientados sobre a vida, privada sobretudo, destas personagens "célebres". Este duplo sentido orienta-nos imediatamente para o carácter profundamente performativo do people. Na verdade, desde que o discurso people se aproprie de um indivíduo, seja de que estatuto for - artista, atleta, cabeça coroada, político, modelo fashion, ou simples anónimo -, erige-o ipso facto em people.

7 No mesmo sentido vai Dakhlia, quando aborda as especulações mediáticas sobre os segredos de alcova dos nossos dirigentes ou ainda as experiências de jogo social criadas sobre a Internet através de vídeos mostrando, sob luz comprometedora, a exibição de um certo número deles ao lado de vedetas do desporto ou do showbiz, fazendo que todos estes fenómenos, entre tantos outros, sejam imputados hoje a uma peopolização galopante da nossa sociedade (Dakhlia, 2010: 6).

8 Aprofundando a noção, pode dizer-se que a peopolização é a extensão da mediatização do mundo do show business a outros meios (político, cultural, desportivo, etc.), à mediatização da vida privada das personalidades, à utilização das vedetas para fins de relações públicas, à fabricação e utilização económica das estrelas do desporto e do show business, inclusive a adoção pelos media generalistas de certos comportamentos da imprensa people, etc.

9 Sem falar, por falta de espaço, do management social, do marketing, constatamos na peopolização, que, ao transformar a vida humana em valor económico, ao substituir cada dia mais a função teológico-política do poder pela racionalidade reificante da gestão, se realiza e se torna um pesadelo a fórmula de Saint-Simon: "Substituir o governo dos homens pela administração das coisas" (Rabinovitch, 2005: 16).

10 É óbvio que quem quiser fazer um pequeno esforço de boa-fé chega à conclusão de que os detentores da ordem social e cultural - por via da peopolização da cultura, do voyeurismo mediático (televisual e internáutico, redes sociais incluídas), expondo os excessos da moda, da remodelação somática, do consumo excêntrico de toda a espécie, do habitat megalómano dos ricos, em resumo, do jet set - são crapulosa e patologicamente narcísicos, alienados e alienantes. É um sistema de entralienação ${ }^{2}$, em que o corruptor rico e produtor, ele próprio idiota na sua relação a si e ao ser, bestializa e reifica a sociedade que se identifica com ele.

11 Há que descrever, até na sua recôndita eidética, os mecanismos da alienação e da reificação das maiorias pelas estruturas de manipulação e de propaganda à escala das tradicionais armas ideológicas do Estado, poderosamente difundidos pela imprensa e sobremediatização jet set, "esculpindo" os ícones propostos às massas no panteão dos "heróis de pacotilha".

12 Iconomania, iconolatria, não se sabe como chamar-lhe, a produção moderna de heróis por imagem - semideuses de palha, enriquecidos no desporto, no cinema ou na apresentação de novelas e nos talk shows, como amostras de um mundo pleno, negando o valor e os sentimentos - constitui, ela própria, o narcisismo inquietante e arrogante de um sistema que ri do povo, que convida, por uma axiologia corrompida e viciada, ao 
frenesi sobre o horror e à imbecilidade, pelo voyeurismo mediático televisual. Como os subdesenvolvidos culturais, o povo desamparado pela sua própria animosidade às ideias e ao recuo interrogador e leitoral, que estas permitem, fica unido ao real, ou melhor, à pseudorrealidade, alucinada e alucinante dos media people, da grande imprensa exuberante e riquíssima, que conserva os plutocratas, na qualidade de modelo para fabricar sonhos ingénuos, segundo uma verdadeira débil onirocracia, à escala da ideologia.

13 A peopolização cria, assim, as suas próprias autossugestões frívolas, e autopromove o seu sinal, por meio da trivialização publicitária. Revistas do estilo people, carros e outros produtos de consumo são objeto de culto. Personalidades dotadas de perfis absolutamente diversos, desde insignificantes atores do entertainment até autênticos criadores, são coroadas. Esse conjunto é acompanhado, ou melhor, iniciado no "brilho da superioridade" (Tarde, 1993) por célebres espaços de jornalismo e de "filosofia" mediática (Rabinovitch, 2005: 22).

\section{O embuste da peopolização}

14 Numa primeira abordagem, sobre a base de um sobreinvestimento coletivo da celebridade, a peopolização surge como um mito naif, segundo o qual a celebridade representa o summum da realização pessoal e do sucesso social.

O tema da celebridade não é raro nem recente, compreendido na cultura de massas. Mas o poder da fascinação da celebridade é hoje levado ao paroxismo pela expansão da lógica people, que, na sua cumplicidade objetiva, com formatos tais como a tele-"realidade", cultiva a atração da celebrização expressa (star system) e a "ilusão de que tudo é possível, cada um tornar-se rei, sem esforço nem talento, apenas com um golpe do acaso, de simulação ou de ornato" (Méjean, 2003: 21; Méjean \& Onteniente, 2003).

16 No campo jornalístico, não pode negar-se que a imprensa de celebridades exibe uma amálgama de faltas deontológicas graves, constituindo uma perigosa investida à qualidade do trabalho da informação, sem que por isso se pretenda subestimar, na sua função comunicacional, a função das revistas especializadas, e, ao mesmo tempo, negar a iniciativa dos media generalistas na sua própria peopolização.

17 Do mesmo modo, assiste-se a igual visão na análise política, em que a peopolização é muitas vezes utilizada como instrumentalização das formas e dos conteúdos people pelos candidatos ou pelos eleitos desejosos de promoverem a sua imagem junto dos eleitores. Os autores e atores da propaganda política não ignoram o potencial ofensivo do discurso people, tendo presente quer as consonâncias quer as dissonâncias entre os usos da peopolização e o conformismo relativo dos media dominantes. O que nos conduz a interrogar a dimensão cívica da peopolização, ou seja, a irrupção do people em política como o terreno do populismo e/ou uma deriva para a inconsistência da "sociedade do espetáculo" (Debord, 1996).

Neste caso, há que olhar a peopolização como construção social. Em primeiro lugar, trata-se de cercar (investigar e descriptar) os objetivos e os interesses de certos atores políticos e mediáticos ao prestarem-se ao jogo da vedetização, depois debruçarmo-nos sobre os públicos - leitores, auditores, observadores, telespectadores, internautas, etc. 
- da peopolização, para verificar os seus usos e efeitos reais e melhor explicar e compreender o sucesso atual da informação people.

Neste contexto, importa enfatizar e denunciar os profetas do embuste, que, na ausência de espírito crítico dos públicos, manipulam, arrombam a consciência dos frequentadores de ilusões. A palavra manipulada consiste em entrar por "arrombamento" no espírito de alguém para aí depositar uma opinião ou provocar um comportamento sem que esse alguém saiba que foi por "arrombamento". A palavra manipulada é, ao mesmo tempo, mentira organizada, privação da liberdade do auditório e utensílio para vencer a sua resistência. A palavra, desde sempre, teve por vocação substituir-se à violência, e tudo o que a fere, fere a democracia. Num primeiro nível: informa; num segundo nível: influencia e, para seduzir, dramatiza. Podemos falar, aqui, de um efeito de entralienação, fusional: a fusão entre manipulador e manipulado, a fim de destruir o último pela repetição (slogan). Importa também recordar que a liberdade de expressão deve acompanhar-se de liberdade de receção e de mediação, o que conduz a refletir sobre o que é a argumentação em relação à manipulação (Breton, 1997), a olhar o fenómeno da peopolização como um meio de enriquecer o debate público (Dakhlia, 2010: 12), e, ao mesmo tempo, estimular a sua desconstrução, despertar o espírito crítico, sem colocar em causa, em circunstância alguma, a liberdade de expressão.

Este é um longo processo preparado, pelo menos, desde a quarta década do século XIX, criando um caldo de cultura propício ao que chamamos hoje peopolização, em que os desiludidos constituem o público-alvo das revistas people, com os seus ingredientes, entre outros, o casting e o casting couch, que aqui se abordam. Esta é, a meu ver, a matriz do casting couch, cujos componentes são vários e se manifestam de modo proteiforme numa lógica de reificação, de "coisificação", que leva à perversidade das práticas empresariais do casting, que, por sua vez, conduz a experiências como o casting couch e a fenómenos radicais, como, em corolário, o homicídio.

O casting couch é a expressão que traduz o fenómeno da prestação de favores sexuais em troca de benefícios profissionais. A situação torna-se mais patente quando carreiras, excessivamente apetecíveis, e tradicionalmente difíceis de conseguir, tais como as indústrias de filmes, televisão, música, moda ou outro tipo de cultura das aparências, são objeto de casting couch, e se constituem em narrativas que incorporam a memória do pequeno acontecimento que inunda as revistas do people, do beautiful people, ou "corde-rosa", e o espaço público. A situação agrava-se quando essas trocas de favores, que são um abuso de poder, podem ganhar enorme visibilidade logo que envolvem escândalo sexual, e, pior ainda, quando atingem um ponto sem retorno e se enleiam no homicídio. No coração da tragédia, a perversidade da ação, a teatralização da conduta predadora e a racionalidade instrumental, uma fantasia, que tece a tela do homicídio, sustentada nos seus coerentes traços com o gozo mortífero (Rabinovitch, 2005: 24).

Um cronista das revistas "cor-de-rosa" acabou por amargar os efeitos de se ter envolvido numa situação radical de casting couch, um caso, suficientemente divulgado pelos media, em curso no Supremo Tribunal de Nova Iorque. O jovem que, alegadamente, o assassinou pretendia mercantilizar o seu corpo para se promover na carreira de modelo fashion. O cronista aproveitou, supostamente, a situação para conseguir o que, obviamente, não conseguiria de outra forma: parceria sexual de um jovem umas décadas mais novo. A situação não é inédita. São bem conhecidos inúmeros casos. Desde sempre que jovens se tornaram amantes de homens ou mulheres, mais 
idosos, com a finalidade de obter benefícios profissionais ou outros. E neste quadro, sempre pode perguntar-se quem é o verdadeiro homicida, o homicida, vítima do casting couch, ou o predador do casting couch?

Pinatel destacou quatro traços da personalidade criminosa para explicar o aparecimento da passagem ao ato: o egocentrismo, a labilidade afetiva, a indiferença e a agressividade. Se transpusermos esses elementos ao que está sendo tecido na cultura contemporânea, poderíamos dizer que todos eles já estão preposicionados (Pinatel, 1991).

A meu ver, no caso presente, ambos são vítimas, porque imersos nesta cultura. Por um lado, pela propagação, pela extensão e pela refração de léxicos embebidos de gozos agressivos ou mortíferos. Por outro, pela colocação na cultura de massa, substituindo os aprendizados pedagógicos, das clericaturas mediáticas, como a nova residência da força formadora de hábito (Panofsky, 1967).

Contaminando os diversos setores de atividade da cultura contemporânea, a racionalidade instrumental, a que assistimos, continua a afirmar o seu domínio. Entretanto, a "heroificação da violência" dos "criminosos do Eu" (Lacan, 2001) coloca em destaque novas silhuetas nas multidões intercambiáveis das democracias de massa. Enquanto isso, o comprometimento lento, a servidão voluntária, a apatia gregária e o gozo por procuração das violências delegadas continuarão a guardar o seu território na espécie humana, como eternos fornecedores de agentes de serviço para as operadoras de engenhos trucidadores (Adorno, 2005: 19).

Poderá isso dizer que já respiramos um ar rarefeito de vida e carregado de toxinas de um assassinato infiltrado? De qualquer modo, a barbárie é comunicativa e gravemente contagiosa (Rabinovitch, 2005: 26).

Como afirma Rabinovitch: "Diríamos, então, que nem o "progresso na vida do Espírito», cuja condição, segundo Freud, estava na renúncia ao gozo absoluto e aos instintos, ou no luto das excessivas satisfações narcísicas; e que nem a erotização amante e respeitosa, intimista e brilhante, fazem parte da Kultur de hoje. Em seu lugar, encontramos: a crueldade, a perversão, o incentivo ao gozo sem limites" (2005: 26).

28 As conveniências de casting são filhas adulterinas das prerrogativas dos predadores sexuais, que pululam em todos os jet sets, e assumem proporções gigantescas de doutrina. Todo o ingénuo, recém-chegado, que for constante nas suas convicções éticas, que não sacrifique os seus sentimentos aos seus interesses pessoais, é premiado com o epíteto de fóssil. Entre o voo das águias e a voracidade dos abutres, os novos sempronius do casting, espumam de raiva quando não podem encontrar sequer um desvio na vida irrepreensível de ilustres mancebos, que procuram neste mercado de trabalho a via para a peopolização.

Prezados pelos jovens moradores das periferias das grandes cidades ou das ruelas dos bairros, falados nas esquinas das ruas, nas festas da alta sociedade, nos cocktails do show biz ou nas antessalas de decisão dos "senhores" do casting, incorporados no imaginário das produções cinematográficas de massa e séries televisivas, os(as) aclamados(as) pelo casting - pequeno ou médio modelo, grande patrão patrocinador do casting capitalista -, tradução padronizada do arquétipo, tendem hoje a incarnar esse protótipo que sabe manter afastado tudo aquilo que diminui o "eu", como escreveu Freud (1969) no seu ensaio sobre o narcisismo (Rabinovitch, 2005: 17). Emergindo da neblina infantil da "cultura do narcisismo", o(a) preferido(a) substitui-se ao herói messiânico do 
imaginário social por uma figura bastante visível e suficientemente simpática para poder ser exaltado.

Evocámos a figura ocorrente do "castingable", do "fashionable", do(a) escolhido(a) do casting, como novo ator social e novo personagem mitológico em vias de substituir a do herói social, que pode ser, e. g., um escritor celebrado.

31 Existe outro personagem no decurso desta construção mítica. Trata-se do predador do casting couch, que é uma segunda personagem, sobre o qual muita coisa começa a ser dita, apesar de carecer de análises mais aprofundadas. Vamos contentar-nos apenas em notar as conexões operacionais, miméticas, descobertas no predador do casting couch, traficante de eventuais influências. Observem-se as indulgências muitas vezes secretamente fascinadas, nesse caso negadas sob o véu de uma hipocrisia de circunstância, concedidas ao predador do casting couch, nas suas afetações.

É, por um lado, um conjunto de manifestações apontadas por Christopher Lasch, sob o nome de "cultura do narcisismo". Elas mostram uma cultura imatura da adolescência infinita, cujo "senhor-criança", e velho ao mesmo tempo, parece incarnar a referência real. Por outro, a adolescência infinita transformada, pelas suas capacidades epidémicas nos comportamentos sociais, em "adolescentismo generalizado" (Lasch, 2006: 269).

33 A afetação do predador do casting couch é sustentada pela permanente lisonja feita à juventude pela televisão, dia após dia, nos chamados reality shows e nos videoclips veiculados pela MTV ou outras. Esta ostentação vive também, na era da segunda modernidade, da desqualificação do princípio do interdito, na confusão políticohistórica entre a figura de Leviatã e a de Behemoth. Entre a figura do Estado total coercivo e a do caos integral da desordem mortal da ausência de Lei. Uma distinção herdada de Hobbes ${ }^{3}$. O pensamento político contemporâneo ainda deve muitos tributos a essa confusão. Conceção inibidora, por repulsão reativa, de qualquer conceção positiva da sanção. Ela esconde-se, enfim, sob a ideologia dos "direitos humanos", que parece apagar qualquer conceção referente aos "deveres" (Rabinovitch, 2005: 20).

Pode falar-se, em ambos os protagonistas, o(a) escolhido(a) do casting e o predador do casting couch, de uma cultura narcísica, elemento constituinte da sociedade do espetáculo, em que o culto do "eu" está imbricado no que pode chamar-se uma cultura do momento e do bem-estar. $O$ narcisismo desenvolve-se através de uma conceção de sucesso social esvaziado da sua substância. Ídolos, personalidades, vivendo plenamente a fantasia narcisista através da celebridade, desempenham um papel proeminente nas nossas sociedades, dando o tom na vida pública privada. Eles são admirados sem limite ou criticados por si próprios e não por aquilo que fazem. Os atos, os motivos da autorrealização, não importam mais. 0 que conta, segundo Lasch, é o sucesso, a fama, a popularidade, em si. Não se procura a aprovação pelo que se faz, mas pelo que parece, pela imagem agradável que é projetada, pela atenção que se conseguiu atirar sobre si, tudo isso devendo ser constantemente renovado e ratificado pela publicidade.

Um facto mimético ocorre também no quadro da política, ou seja, o político "moderno [que] pouco cuidado manifesta relativamente a trabalho a fazer [...]. O que lhe interessa é persuadir, seduzir e ganhar o «público interessado» [...]. Confunde o sucesso com a tarefa a realizar, com a impressão que ele produz ou tenta produzir sobre os outros" (Lasch, 2006: 95).

$36 \mathrm{Na}$ moderna comunicação, o importante não é verdadeiro nem falso. O que é importante é que pareça credível. Os factos são substituídos por declarações fiáveis. 
Propagandear não é mais fazer circular informações tendenciosas, mas verdades parciais com estatísticas truncadas. Para surgir o mais credível e persuasivo possível, a burocracia deve usar a linguagem mais técnica e mais abstrata, o mais exequível, com o objetivo de fazer admitir que a gestão pública está nas mãos de especialistas, que gerem problemas ininteligíveis para o homem comum (Lasch, 2006: 112;114). Agora que a política se tornou um espetáculo, a arte tende, cada vez mais, a esbater as fronteiras entre realidade e ilusão, ou espectadores e atores, pretendendo apresentar seja uma versão mais intensa da realidade, seja, ao contrário, uma absurda representação de uma vida vazia. Citando Guy Debord, Lasch evoca a propaganda da mercadoria, que emancipa as mulheres e as crianças contra a autoridade patriarcal, para melhor submeter, cada um, ao paternalismo da publicidade, das empresas industriais e do Estado. A publicidade incentiva tanto a satisfação de todos os desejos como a incerteza. Ela cria necessidades, sem as satisfazer, e concebe novas ansiedades. Incentiva o consumidor ao fascínio pela celebridade, a cultivar gostos extraordinários, para se identificar com os gostos de elites dominantes. Mas, promovendo estas aspirações grandiosas, leva ao desprezo e ao descrédito de "si" (Lasch, 2006: 108; 111; 228).

Daí a "anti-idade" das mulheres, ou dos homens, que "injetam" botox nas suas rugas, e o reflexo no escalão etário, sem ritual de passagem, das meninas pré-púberes, que tomam ares de "donzelas", exibindo posturas de Lolita, de segunda categoria, ou dos moços pré-adolescentes, que ostentam atitudes de figuras da popmusic, de terceira ou quarta ordem, em cujo saco se encontram patins e outros brinquedos, que se tornam o seu complemento desmitificador.

\section{Conclusão}

Uma verdadeira anomia lexical, com acéfalo carácter epidemiológico, faz que a imprensa, na sua expansão imitativa, designe sob o mesmo lexema tanto os autênticos opositores políticos quanto os traficantes de influências ou tarefeiros da política patenteados, os fashionables do casting, os grupos variados de agentes do casting ou predadores do casting couch. Esta atitude vale, também, tanto para a cobertura jornalística de combates nobres quanto para as crueldades e as atrocidades sem nome. Esta disposição elimina qualquer possibilidade de avaliação moral, de referências éticas sobre os motivos que animam esses atores e as suas ações, gerando confusão entre os limites do admissível e do condenável, do proscrito e do aceitável.

Portugal corre o risco de tornar-se um descomunal palco "cor-de-rosa", com a cumplicidade da indecorosa exibição dos empreiteiros da política e dos agentes da vida pública, com graves sequelas sociais, ausência de espírito cívico e espírito crítico, agravada e aprofundada, neste quadro, pela intervenção obscena, cabotina, displicente, egocêntrica e dissimulada dos media. Ou seja, a intercomunicabilidade entre paradigmas, que, com grande acuidade, torna visível a irrecusável e atual crise dos media, mostra um processo agudizado que é, tendo presente honrosas exceções, fruto de uma mistura explosiva de informação totalitária, jornalismo banal, lugares-comuns, negócios de família, "piqueteiros", "faxineiros" e "guarda pretoriana" dos conglomerados mediáticos. Dito de outro modo, a imprensa escrita e audiovisual é dominada por um jornalismo de interesse, por enredos de cumplicidade, por agregados industriais e financeiros, por uma ideia de mercado. Um pequeno grupo de ubíquos 
plumitivos impõe a sua definição de informação/mercadoria a uma atividade cada vez mais fragilizada pelo pavor do desemprego.

Apropriando e adequando Cohen, posso dizer que a espiral perversa do casting couch começa com algum ato "desviante". O desvio é geralmente criminoso, mas pode envolver, também, atos legais considerados moralmente repugnantes pela maioria da sociedade. Os media relatam o que consideram ser, do seu ponto de vista, interessante, mas o novo enfoque sobre a questão revela ocultos, ou na fronteira, exemplos, que não são atraentes, e apenas confirmam o "padrão" (Cohen, 1990). Narrados os casos de tal "desvio", estes são muitas vezes apresentados como apenas "o que se sabe" ou "a ponta do véu", uma declaração que é quase impossível de refutar imediatamente. Por uma variedade de razões, o que é assustador, e iria ajudar o público, a perspetiva racional tende a ser ignorada pelos media.

41 Como resultado, os pequenos problemas começam a ser olhados de modo sério e o casting couch começa a surgir como comum. O público é motivado para se manter informado sobre esses acontecimentos. A publicidade instrumental resultante tem potencial para aumentar o comportamento "desviante", fascinante, tornando-o comum ou aceitável. Na fase seguinte, a curiosidade mórbida do público sobre o casting couch força normalmente os media a concentrar mais recursos para lidar com o desvio específico muito mais do que ele merece.

42 Em seguida, plumitivos e comentadores tecem, sob pressão da "opinião pública", os mais desfavoráveis ou benignos comentários para conseguirem mais público e aumentarem a sua popularidade e vedetismo, ganhando o direito a entrarem na galeria dos nomeados para frequentar festas, ou pré-estreias, do jet set paroquial, dando a impressão de que estão a lidar com uma questão fundamental para o país e para a democracia.

43 Esta situação agrava-se numa conjuntura em que os media consagram um largo espaço ao tratamento irresponsável do pequeno acontecimento ou consideram como "liberdade de informar" os seus meneios mercantis. E, neste contexto, caso necessário, os antigos deificados são transformados em algozes, que, depois de incriminados sem processo, são reabilitados, inocentados e, posteriormente, metamorfoseados em heróis patéticos.

44 A democracia e o regime democrático correm perigo quando quem detém o poder dos media alimenta de "dia" para "matar" à "noite", o mesmo é dizer exibe à luz do dia as formalidades da democracia, para ab-rogar os seus princípios na trama da obscuridade e da ocultação. Predadores por excelência, os media da segunda modernidade vão nutrir, numa primeira fase, o público com propostas de suposta autenticidade e presumível informação honesta e, em seguida, dar "morte" ao espírito crítico, numa manifestação sinistra de concubinato entre o trivial e o crucial, em que, na verdade, não consegue distinguir-se, na ausência de espírito crítico, antes nulificado, o importante do acessório.

45 Todo este quadro tende a convencer o público de que a sua curiosidade mórbida é justificada, enquanto os media continuam a desfrutar por terem à sua disposição relatórios de outras atividades de casting couch, que perpetuam a espiral, no seio da qual os seus figurantes, a maioria de opereta, patenteiam uma indigência de celebrização que é complexa e não se explica facilmente. Aquém destas manifestações de casting 
couch, subsiste uma complexa realidade, que se articula com a necessidade de mitificação, olhada como horizonte de chegada para todas elas.

Os people recrutam-se em todos os meios e sabemos, pelo menos depois do aparecimento da tele-"realidade", que não têm de apresentar um talento particular, porque, no olhar da cultura contemporânea da celebridade, só conta desde logo o grau de notoriedade. Na sua aceção mais lata, a peopolização é uma realidade coextensiva a um sistema ideológico, fundado sobre o valor da mediatização pessoal, um produto que se mercantiliza. Ela será, pois, equivalente à "cultura da celebridade", celebrity culture, que, segundo alguns investigadores anglo-saxónicos, seria o pivô da pós-modernidade. São precisamente as questões ideológicas da celebridade que estão na origem do seu carácter interpelatório (Barthes, 2001: 210) enquanto mitologia do século XXI. Não faz sentido, senão em relação à ordem social, que a peopolização convoque interpretações normativas e ofereça deste facto duas versões míticas contrastadas.

Com efeito, a iconolatria people (celebrização), que subjaz a este combate, no duplo sentido de culto das vedetas e da paixão da imagem, é indissociável do processo das aparências, como da demonização das celebridades mediáticas. Aqui reside, sem dúvida, a originalidade maior do mito da celebrização deste período: a capacidade de integrar a sua própria desmitificação.

Finalmente, não será ousado afirmar que a atividade do casting couch constitui o "lado negro" do fenómeno da peopolização, no caso aqui em apreço agravado pela sua manifestação mais radical: o homicídio.

Vários sucedâneos da peopolização - por economia do presente texto não serão aqui desenvolvidos -, como formas e vias de, pessoalmente, sublimar a frustração do insucesso, são ingredientes básicos deste quadro, que articula organicamente peopolização, hiperconsumo, sentimentos de autoestima e de narcisismo, um processo que conduz ao que posso chamar a ideologia do espetáculo.

Se quisermos, trata-se de um género menor de representação "teatral", em que as sucessivas ladainhas não são livros nem obras, mas uma vontade de hipervisibilidade, de ser people. Neste sentido, estas litanias são um modo de ganhar a vida expondo o corpo, bem visível, seja nas suas variações sobre as quais se apoia a campanha de propaganda, seja num sistema de ecos, que se torna ressonância lírica nos aspirantes à peopolização. O corpo dá-se em espetáculo, como a pseudorrealidade se dá em representação, que se repete com todas as tonalidades pelos séquitos e acompanhantes. Existe uma espécie de movimento, uma dialógica entre o peso da ideologia do espetáculo e um apelo profundo ao imaginário ilusionista, correspondendo a toda a crença na peopolização, que se esforça por ultrapassar a condição de representação, no sentido de tornar-se uma outra encenação, mais próxima da festa, dos rituais mágicos, das práticas encantatórias de toda a peopolização.

51 Todavia, o acontecimento aqui em apreço vai mais além, ao penetrar a via da profanação da fronteira entre pseudorrealidade e mundo-de-vida, quando exibe a tendência de teatro da "crueldade", que acaba por metamorfosear a figuração do proscénio, no que pode chamar-se o espetáculo da morte, a "morte que se dá em espetáculo", que o homicida pretende se atinja pelo viés da impressionabilidade, numa hiperbolização do "eu". 


\section{BIBLIOGRAFIA}

ADORNO, T. (2005), “Éduquer après Auschwitz”, in Le Monde de l'éducation 338 (07/08/2005).

ALLARD, L. (2010), Mythologie du portable, S. l., Le Cavalier Bleu éditions, coll. Myth'O.

BARTHES, R. (2001), Mythologies, Paris, Seuil.

BRETON, P. (1997), L'Utopie de la Communication, Paris, La Découverte/Poche.

COHEN, S. (1990), Folk devils and moral panics: the creation of the mods and rockers, Oxford (GB), Basil Blackwell.

DAKHLIA, J. (2010), Mythologie de la peopolisation, S. 1., Le Cavalier Bleu éditions, coll. Myth'O.

DAKHLIA, J. (2007), “Celebrity and Politics: An Unnatural Partnership? The Role of Celebrity Magazines in the French Politicians' Media Coverage”, in Questions de Communication, N. 12, Nancy, Presses Universitaires de Nancy.

DEBORD, G. (1996), La Société du spectacle, Paris, Gallimard, coll. Folio.

ESQUENAZI, J.-P. (2009), Mythologie des séries télé, S. 1., Le Cavalier Bleu éditions, coll. Myth'O.

FREUD, S. (1969), "Pour introduire le narcissisme", in Sigmund Freud, La Vie sexuelle, traduit de l'allemand par Denise Berger, Jean Laplanche et collaborateurs; introduction [par le Dr] Jean Laplanche, Paris, PUF.

LACAN, J. (2001), "Prémisses à tout développement possible de la criminologie”, in J. Lacan, Autres écrits, Paris, Le Seuil.

LASCH, C. (2006), La culture du narcissisme, trad. Michel Landa, Paris, Champs-Flammarion.

LIPOVETSKY, G. (2006), Le bonheur paradoxal: essai sur la société d'hyperconsommation, [Paris], Gallimard.

MARSHALL, P. D. (2004), Celebrity and Power. Fame in Contemporary Culture, Minneapolis, University of Minnesota Press.

MÉJEAN, J.-M. (2003), "Les médias entre people et populisme", in MédiaMorphoses, n.. 8, "Médias people: du populaire au populisme", Paris, Armand Colin, pp. 21-24.

MÉJEAN, J.-M. e F. Onteniente (2003), L'école au coeur: allegro ma non troppo, Nîmes, C. Lacour.

PANOFSKY, E. (1967), Architecture gothique et pensée scolastique, Paris, Minuit.

PINATEL, J. (1991), La personnalité criminelle, Toulouse, Éres.

RABINOVITCH, G. (2005), “Figuras da Barbárie” [Figures of barbarism], in Psicologia em Revista, traduzido do original por Nina de Melo Franco, Belo Horizonte, s. n., vol. 11 (N.o 17, junho), pp. 11-28.

ROJEK, C. (2001), Celebrity, Londres, Reaktion Books Ltd.

TARDE, G. (1993), Les Lois de l'imitation, Paris, Kimé.

TURNER, G. (2004), Understanding Celebrity, Londres, Sage.

VEBLEN, T. (1970), Théorie de la classe de loisir, traduit de l'anglais par Louis Évrad; précédé de “Avez-vous lu Veblen?" par Raymond Aron, Paris, Gallimard.

WOLTON, D. (2006), É preciso salvar a comunicação, São Paulo, Paulus. 
WOLTON, D. (2007), Sauver la communication, Paris, Flammarion.

\section{NOTAS}

1. O recurso a neologismos torna-se, neste texto, inevitável e indispensável, face à simplicidade do seu universal significado, para melhor identificação com o tema. Adequa-se aqui o termo peopolização, a partir do vocábulo em idioma francês, peopolisation, que remete para o termo em língua inglesa people. $\mathrm{O}$ que se entende, exactamente, por peopolização? A etimologia da palavra conduz, na ocorrência, ao termo people. De toda a maneira é necessário saber de que people se fala. A adequação à língua portuguesa, que aqui faço, do vocábulo da língua francesa peopolisation e da palavra inglesa people, à partida sinónimo de "povo" ou de "gente", realiza-se à custa da contração da sua significação.

2. A entralienação deve ser entendida como a reprodução da vítima segundo a imagem do carrasco, a mútua colaboração do alienado e do alienante no ato desumano de aniquilar.

3. No livro Behemoth or the Long Parliament, diferentemente dos anteriores trabalhos Leviatã e Do Cidadão, Hobbes desenvolve uma narrativa histórica sobre guerra civil na Inglaterra compreendida entre o período de 1640 e 1660. Se um dos significados simbólicos assumidos pelo Leviatã de Hobbes é o de um Estado garantidor da paz, o Behemoth simboliza a rebelião e a guerra civil.

\section{RESUMOS}

Este texto tem vários e diversificados ingredientes, uma panorâmica contributiva para a tentativa de compreensão de um horizonte de chegada: o homicídio, fenómeno radical do casting couch, no quadro da cultura da peopolização, um processo que se inicia no incontrolável desejo de "ser" people. Cada um, entre nós, tem uma propensão a comparar-se aos outros e a procurar, por tal ou tal traço exterior, uma pequena superioridade, uma diferença simbólica em relação às pessoas com as quais convive. A natureza humana não se reduz a este traço, não se trata de julgá-la de um ponto de vista moral, apenas se constata. Em cada classe, os indivíduos tomam como modelo o comportamento em vigor na classe social superior. Este longo processo é o caldo de cultura propício ao que hoje chamamos peopolização, em que os desiludidos constituem o público-alvo das revistas people, com os seus ingredientes, entre outros, o casting e o casting couch, que aqui se abordam.

This text has several and diversified ingredients, a contributively overview for the attempt of the understanding of an arrival horizon: the homicide, radical phenomenon of the casting couch, in the culture's framework of the culture of the peopolization, a process that begins in the uncontrollable desire of "being" people.

Each one, among us, has a propensity to compare himself to the others and to seek, by such or such external line, a small superiority, a symbolic difference regarding to people with whom they live together. The human nature is not reduced to this line, it is not a matter of judging it from a moral point of view, but it is just faced here. In each class, the individuals take as model the ruling behaviour in the superior social class. This long process is the favourable culture breeding ground, we call to which peopolization, where the disappointed themselves constitute the target 
audience of the people' magazines, with their ingredients, among others, the casting and the casting couch, that are here addressed.

\section{ÍNDICE}

Keywords: Peopolization, media, people, casting couch

Palavras-chave: Peopolização, media, people, casting couch

\section{AUTOR}

\section{JOSÉ AUGUSTO DOS SANTOS ALVES}

Doutor e Agregado em História e Teoria das Ideias pela Faculdade de Ciências Sociais e Humanas, Universidade Nova de Lisboa, Portugal, professor e investigador no Centro de História da Cultura, CHC, Faculdade de Ciências Sociais e Humanas, Universidade Nova de Lisboa, Portugal (jsalves@fcsh.unl.pt) 